Revista Estudios, (38), 2019.

Junio 2019-Noviembre 2019

ISSN 1659-3316

Morales Harley Roberto

\title{
II Sección
}

Dos aspectos del quehacer universitario y un estudio del desarrollo rural

\section{Años de Sánscrito en la Universidad de Costa Rica}

Roberto Morales Harley
Universidad de Costa Rica, Costa Rica
roberto.moralesharley@ucr.ac.cr
https://orcid.org/0000-0002-4752-8588

Recibido: 10 de diciembre de 2018

Aceptado: 16 de abril de 2019

Resumen: En 1968, la profesora emérita y humanista costarricense Hilda ChenApuy Espinoza, quien había recibido una beca de la UNESCO para estudiar las culturas asiáticas y fortalecer así el vínculo Oriente-Occidente, inaugura los estudios de sánscrito en la Universidad de Costa Rica. Este artículo busca reseñar la historia de los estudios sobre el sánscrito y la India en Costa Rica, contextualizar la enseñanza de esta lengua clásica indoeuropea en la Universidad de Costa Rica y defender tanto su relevancia en el mundo hispánico como su vigencia para la sociedad actual. Las conclusiones señalan la pertinencia de la inclusión del sánscrito en el Departamento de Filología Clásica en aspectos como promover el aprendizaje de lenguas, fortalecer los conocimientos gramaticales, estudiar las civilizaciones antiguas, valorar a los pueblos actuales, preservar las manifestaciones culturales, defender el patrimonio humano y ofrecer puntos de encuentro entre el pasado y el presente, entre Oriente y Occidente, entre India y Costa Rica.

Palabras clave: sánscrito; Universidad de Costa Rica; filología clásica; lenguas clásicas indoeuropeas; estudios indológicos hispanoamericanos

\section{Years of Sanskrit at the University of Costa Rica}

Abstract: In 1968, professor emeritus and Costa Rican humanist Hilda Chen-Apuy Espinoza, who had received a UNESCO scholarship to study Asian cultures and to strengthen the East-West bond, inaugurates Sanskrit studies at the University of Costa Rica. This paper seeks to review the story of Sanskrit and Indian studies in

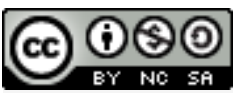

La Revista Estudios es editada por la Universidad de Costa Rica y se distribuye bajo una Licencia Creative Commons Atribución-NoComercial-CompartirIgual 3.0 Costa Rica. Para más información envíe un mensaje a 
Costa Rica, to contextualize the teaching of this Indo-European classical language at the University of Costa Rica, and to defend both its relevance in the Hispanic world and its validity for modern society. The conclusions point out the pertinency of including Sanskrit in the Department of Classical Philology, in ways such as promoting language learning, strengthening grammatical knowledge, studying ancient civilizations, valorizing contemporary groups, preserving cultural productions, defending human patrimony, and offering meeting points between past and present, between East and West, between India and Costa Rica.

Key Words: Sanskrit; University of Costa Rica; Classical Philology; Indo-European Classical Languages; Hispanic Indological Studies.

A doña Hilda Chen-Apuy Espinoza (in memoriam) y a doña Sol Argüello Scriba, respectivamente, pionera y continuadora de los estudios de Sánscrito en Costa Rica, porque la tradición es la única forma de vivir la Antigüedad en la actualidad.

\section{Introducción}

En su artículo titulado La lengua sánscrita, llegada y permanencia en Costa Rica, la profesora Sol Argüello (1989) indica que, en la Universidad de Costa Rica, la cátedra de Sánscrito comienza en el segundo semestre del año 1968, por lo que en este segundo semestre del año 2018 se celebran 50 años de labor ininterrumpida en la enseñanza de esta lengua clásica de la India en nuestra alma mater.

Para conmemorar dicha efeméride, el Departamento de Filología Clásica y el Programa Permanente de Extensión Docente, ambos de la Escuela de Filología, Lingüística y Literatura de la Universidad de Costa Rica, han unido esfuerzos en la organización de una serie de actividades el 31 de octubre en la Facultad de Letras de esta casa de estudios.

\section{(ब) $\odot \odot$}

La Revista Estudios es editada por la Universidad de Costa Rica y se distribuye bajo una Licencia Creative Commons Atribución-NoComercial-CompartirIgual 3.0 Costa Rica. Para más información envíe un mensaje a 


\section{El sánscrito y los estudios sobre la India en Costa Rica}

La historia de los estudios sobre el sánscrito y sobre la India en nuestro país se remonta, como precedentes, a dos grandes educadores costarricenses: don Roberto Brenes Mesén (1874-1947) y don Omar Dengo (1888-1928). De acuerdo con los datos del Departamento de Investigación y Bibliografía de la Biblioteca Nacional Miguel Obregón Lizano (2002), don Roberto Brenes Mesén, a raíz de sus estudios de filología en Chile, se interesa por lenguas como el latín, el griego antiguo y el sánscrito. Sobre esta última, cabe destacar su donación del libro A Sanskrit Primer, del sanscritista estadounidense Edward Delavan Perry (1854-1938), a la Biblioteca Carlos Monge Alfaro, puesto que tal libro representa el primer método con el que se empieza a enseñar sánscrito en Costa Rica. A su vez, según el estudio de Argüello (1989), don Omar Dengo se habría adentrado en el sánscrito de manera autodidacta, por medio del citado libro de Perry.

El hito en la consolidación de los estudios sobre la India en Costa Rica se remonta a la década de 1960. En ese entonces, la profesora Clara Corneli Marocchi (1922-1994), coordinadora de la Sección de Estudios Clásicos, y el profesor Arturo Agüero Chaves (1907-2001), director del Departamento de Filología, invitaron a la profesora Hilda Chen-Apuy Espinoza a impartir clases de sánscrito en la Universidad de Costa Rica (Argüello, 1989, p. 63). La profesora Chen-Apuy tuvo a su cargo la asignatura desde 1968 hasta su jubilación en 1984. Luego, la profesora Sol Argüello Scriba lo asumió desde 1984 hasta su jubilación a inicios de este 2018.

Actualmente, en el marco del proceso de Autoevaluación que atraviesa la Escuela de Filología, Lingüística y Literatura, conviene señalar que los estudios sobre la India, en el seno del Departamento de Filología Clásica, constituyen uno de los pilares fundamentales en la formación de profesionales en Filología Clásica ${ }^{1}$. A los cursos FL-3009 Sánscrito Básico I y FL-3010 Sánscrito Básico II se ha sumado el curso FL-5224 Literatura Sánscrita como materia troncal del

La Revista Estudios es editada por la Universidad de Costa Rica y se distribuye bajo una Licencia Creative Commons Atribución-NoComercial-CompartirIgual 3.0 Costa Rica. Para más información envíe un mensaje a 
Bachillerato en Filología Clásica. Además, los cursos FL-1041 Mitología de la India y FL-3157 Rabindranath Tagore y su obra se ofrecen como optativos para el Bachillerato en Filología Clásica y para el Bachillerato en Filología Española, y los cursos FL-3109 Sánscrito Intermedio I, FL-3110 Sánscrito Intermedio II, FL-4147 Sánscrito Avanzado I y FL-5147 Sánscrito Avanzado II se ofrecen como optativos para la Licenciatura en Filología Clásica y para la Licenciatura en Filología Española.

\section{El sánscrito como lengua clásica indoeuropea en la Universidad de Costa Rica}

En su estudio acerca de la noción de sánscrito clásico, Müller y Orqueda (2016) proponen cuatro criterios para abordar el sánscrito, de los cuales se siguen, respectivamente, cuatro concepciones de la lengua sánscrita: el criterio histórico resulta en el sánscrito como "lengua clásica, equivalente al griego y al latín" (Müller y Orqueda, 2016, p. 108); el criterio lingüístico, en el sánscrito como variedad lingüística natural; el criterio discursivo-textual, en el sánscrito como lengua del canon literario, y el criterio cultural, en el sánscrito como variedad lingüística artificial.

Si bien la pluralidad no deja de ser problemática, es posible una visión unificadora al entender al sánscrito como una lengua clásica indoeuropea. Esto permite no solo distinguirlo de otras lenguas consideradas clásicas en virtud de la cantidad y calidad de obras literarias antiguas compuestas en ellas (como el sumerio y el acadio, el hebreo y el árabe, el chino y el japonés, el náhuatl y el quechua, por ejemplo), sino también enfatizar el vínculo del sánscrito con el griego antiguo y el latín.

Como lengua indoeuropea, el sánscrito pertenece a la rama indoirania (junto con lenguas como el avéstico y el persa antiguo), específicamente al subgrupo indoario (junto con lenguas como el védico, el pāli, el ardhamāghadhī, el

\section{(c) (i)(2)}

La Revista Estudios es editada por la Universidad de Costa Rica y se distribuye bajo una Licencia Creative Commons Atribución-NoComercial-CompartirIgual 3.0 Costa Rica. Para más información envíe un mensaje a 
apabhramśa, el hindi, el bengalí, entre muchas otras), y es, por tanto, pariente lejano del español, dentro de la familia lingüística más grande de la actualidad, tanto por extensión geográfica como por cantidad de hablantes.

Como lengua clásica, el sánscrito se refiere, en sentido restringido, a la forma literaria del indoario antiguo que se empleó entre el siglo I a.C. y el siglo VII d.C., o, con mayor precisión, durante la Época Gupta (siglos IV-VI d.C.); y, en sentido amplio, a la forma culta que, desde los Vedas hasta las obras literarias compuestas hoy en día, cuenta con una tradición ininterrumpida de más de 3500 años y con una producción de más de 90000 obras (Mylius, 2015).

En su artículo Lo clásico: Una interpretación y una reflexión, la profesora Estébana Matarrita (1989) entiende lo clásico como el "principio integrador de la unidad orgánica" (p. 58) y define la filología como "arte de comprender, explicar y restablecer la tradición literaria" (p. 57). En este sentido, no solo es el sánscrito una lengua clásica, preocupada desde sus orígenes por la relación fondo-forma (valga decir, forma visual de la escritura, pero, sobre todo, forma sonora de la lengua), sino que también tiene cabida dentro de la filología clásica, disciplina que, más que las meras letras, lee, en los textos, las culturas.

Por su parte, en su artículo La pertinencia de la enseñanza del sánscrito en el plan de estudios de Filología Clásica, la profesora Sol Argüello (2012) defiende que el estudio del sánscrito contribuye en la formación del profesional en filología clásica en aspectos como el léxico, por medio del análisis de raíces cognadas; la morfología, a través de la revisión del uso de los casos; la fonética y la sintaxis de las otras lenguas clásicas, gracias a ciertas bases lingüísticas y gramaticales; la consolidación de los conocimientos sobre el español como lengua materna, por la vía de la comparación; el espacio de enriquecimiento cultural que ofrecen la literatura y la mitología de la India; y la ruta de acceso hacia otras lenguas indoeuropeas y también asiáticas.

\section{(c) (i) (2)}

La Revista Estudios es editada por la Universidad de Costa Rica y se distribuye bajo una Licencia Creative Commons Atribución-NoComercial-CompartirIgual 3.0 Costa Rica. Para más información envíe un mensaje a 
ISSN 1659-3316 Morales Harley Roberto

En este sentido, al incluir el Sánscrito como parte de los Estudios Clásicos, la Universidad de Costa Rica se halla al lado de grandes universidades a nivel mundial, como la UNAM², en México; la UBA ${ }^{3}$, en Argentina; São Paulo, en Brasil ${ }^{4}$; Brown $^{5}$, Cornell ${ }^{6}$, Lebanon Valley ${ }^{7}$, New York $^{8}$, Florida ${ }^{9}$, Georgia $^{10}$, Vermont ${ }^{11}$ y Rochester $^{12}$ en Estados Unidos; Concordia ${ }^{13}$, en Canadá; la Complutense ${ }^{14}$, Salamanca ${ }^{15}$ y Oviedo $^{16}$, en España; y Oxford ${ }^{17}$, en Inglaterra.

\section{La enseñanza del sánscrito en la Universidad de Costa Rica en el marco de los estudios indológicos hispanoamericanos ${ }^{18}$}

Dos rasgos característicos del profesional en Filología Clásica son su preocupación por la terminología en lengua original y su curiosidad por el estudio etimológico. Las premisas que subyacen a este peculiar proceder son, por una parte, que las palabras no solo poseen un nivel denotativo, sino también uno connotativo, y este solo se alcanza en contexto; $y$, por otra parte, que una de las formas de comprender el presente mediante la palabra es remontarse a la historia de las palabras.

Sánscrito, en sánscrito, se dice saṃskrtam. Lengua sánscrita, en sánscrito, se dice samskṛtā bhașā. Tanto el adjetivo sustantivado como el especificativo se forman de la unión del prefijo sam- (junto con, por completo) y el participio perfecto krta (hecho), derivado de la raíz $K R$ (hacer). En un sentido próximo al del latín perfectum, el sánscrito es, según su etimología, la lengua perfecta.

Si en la mitología krta yuga (la edad perfecta) representa una especie de época dorada en la que el orden triunfa sobre el desorden y la justicia sobre la injustica, de manera similar, en la gramática samskḳtā bhașā (la lengua perfecta) representa una forma lingüística de gran corrección, en la que "nada falta ni nada sobra", por usar una expresión de la profesora Chen-Apuy. Como tal, la lengua sánscrita fue codificada, desde el siglo IV a.C., por el gramático indio Pāṇini, autor

\section{(ब) $\odot \odot$}

La Revista Estudios es editada por la Universidad de Costa Rica y se distribuye bajo una Licencia Creative Commons Atribución-NoComercial-CompartirIgual 3.0 Costa Rica. Para más información envíe un mensaje a 
del célebre Aștāādhyāyī (Las ocho lecciones), una obra pionera en su género en el mundo.

En la Universidad de Costa Rica, cuando, en el cuarto año de la carrera, el estudiante de Filología Clásica, incluso con buenas bases de español, latín y griego antiguo, se enfrenta a esta lengua, el sánscrito generalmente lo abruma: en el peor de los casos, en la tercera acepción del verbo abrumar (Real Academia Española, 2014), esto es, 'producir tedio o hastío'; en el mejor de los casos, en su cuarta acepción, es decir, 'producir asombro o admiración'.

Frente a las 23 letras del alfabeto en latín, las 24 en griego antiguo y las 27 en español, el sistema de escritura devanāgarī (la ciudad de los dioses) posee 48 caracteres. Frente a las 3 conjugaciones del español y las 4 del latín, hay 10 clases de raíces verbales sánscritas. Frente a las 2 contracciones del español y las cerca de 15 reglas de contracción del griego antiguo, en sánscrito hay más de 70 reglas de sandhi (combinación de sonidos en la pronunciación) y más de 200 ligaduras (combinación de caracteres en la escritura). Y, frente a la sintaxis de subordinación característica de las otras tres lenguas mencionadas, el sánscrito privilegia las formas nominales, con 4 tipos de compuestos, cuya asombrosa extensión rivaliza, por ejemplo, con la de este tipo de construcciones en alemán.

A primera vista, el sánscrito se aparece ante el alumno como el Himalaya ante el montañista: por cada gran cima alcanzada, siempre hay una más grande detrás. No en vano la misma civilización que nos dio el yoga, esa refinada técnica consistente en un esfuerzo extremo emparejado con una disciplina aún mayor, nos obsequió también esta verdadera prueba a la paciencia. Los antiguos indios lo tenían muy claro: "la gramática se aprende en 12 años”, decían.

Cuando la profesora Hilda Chen-Apuy Espinoza recibió la invitación para impartir un curso de sánscrito en la Universidad de Costa Rica, se encontraba cursando estudios en la Universidad de Cambridge (Argüello, 1989, p. 63). Por

\section{(c) (i) (-)}

La Revista Estudios es editada por la Universidad de Costa Rica y se distribuye bajo una Licencia Creative Commons Atribución-NoComercial-CompartirIgual 3.0 Costa Rica. Para más información envíe un mensaje a 
razones históricas, los primeros estudiosos occidentales en acercarse de manera sistemática al sánscrito fueron ingleses.

Con la expansión europea de los siglos XV-XVIII, el sánscrito y otros bienes inmateriales viajaron, junto con las especias y otros productos tangibles, hacia Occidente. Se suele atribuir al erudito anglo-galés Sir William Jones (1746-1794) el mérito de haber puesto en relación, por primera vez, las lenguas europeas con las indias, en su discurso del 2 de febrero de 1786 ante la Sociedad Asiática de Bengala:

La lengua sánscrita, sea cual sea su antigüedad, posee una estructura maravillosa; más perfecta que el griego, más abundante que el latín y más exquisitamente refinada que ambas, pese a guardar con ellas, tanto en las raíces verbales como en las formas gramaticales, una afinidad mayor de la que podría haber resultado por casualidad; tan grande, en efecto, que ningún filólogo podría examinar las tres sin creer que surgieron de alguna fuente común, que probablemente ya no existe. Hay una razón similar, si bien no tan evidente, para suponer que el gótico y el celta, aunque mezclados con una lengua diferente, tuvieron el mismo origen que el sánscrito; el persa antiguo podría añadirse a la misma familia. (Burrow, 1965, p. 6; traducción del autor de este trabajo)

La línea comparatista fue continuada por el lingüista alemán Franz Bopp (1791-1867), así como por el filólogo y orientalista alemán Friedrich Max Müller (1823-1900), quienes se suelen vincular, respectivamente, con los orígenes de la filología y la lingüística comparadas, por un lado, y de la mitología y las religiones comparadas, por el otro. Más adelante vendrá también la literatura comparada. En esta línea de ideas, no hay que olvidar que, en la Universidad de Costa Rica, no solo son la lengua, la mitología y la literatura las secciones principales del Departamento de Filología Clásica, sino que también la Filología Clásica, la

\section{(c) (i) (2) (2)}

La Revista Estudios es editada por la Universidad de Costa Rica y se distribuye bajo una Licencia Creative Commons Atribución-NoComercial-CompartirIgual 3.0 Costa Rica. Para más información envíe un mensaje a 
ISSN 1659-3316

Junio 2019-Noviembre 2019

Morales Harley Roberto

Literatura y la Lingüística integran los tres departamentos de la Escuela de Filología, Lingüística y Literatura.

El imperialismo británico y el romanticismo alemán ocasionaron que fueran estos los primeros países europeos en interesarse por el sánscrito. Actualmente, tales países continúan siendo referentes a nivel mundial en el ámbito de la Indología. En Gran Bretaña, hay cuatro universidades ${ }^{19}$ que imparten sánscrito: Oxford, Cambridge, Londres y Edimburgo; en Alemania, hay trece ${ }^{20}$ : Berlín, Bonn, Friburgo, Gotinga, Halle, Hamburgo, Heidelberg, Kiel, Leipzig, Marburgo, Múnich, Tubinga y Wurzburgo. A estas se suman una larga lista ${ }^{21}$ de centros de educación superior en Europa, Asia (India, sobre todo), Oceanía y América.

En el mundo hispánico, los estudios sánscritos comienzan, ligados a los estudios clásicos, en España. Tras el significativo precedente de Francisco García Ayuso (1835-1897), considerado "el primer indoeuropeísta e indoiranista español" (Álvarez-Pedrosa, 1994, p. 66), la fecha clave es 1877, año de creación de "la primera cátedra de sánscrito española" (Álvarez-Pedrosa, 1994, p. 61). Para 1897 (García, 2008, p. 10), el profesor Mario Daza de Campos (1860-1943) es nombrado catedrático de Lengua y Literatura Sánscrita en la Facultad de Filosofía y Letras de la Universidad de Madrid, puesto que ocupa hasta su jubilación en 1933. En su proemio a la traducción del Ratnāvalí (El collar de perlas) de su discípulo Pedro Urbano González de la Calle (1879-1966), Daza celebra la inclusión de los estudios sánscritos como parte de los estudios clásicos del siguiente modo:

\section{(c) (1) (2)}

La Revista Estudios es editada por la Universidad de Costa Rica y se distribuye bajo una Licencia Creative Commons Atribución-NoComercial-CompartirIgual 3.0 Costa Rica. Para más información envíe un mensaje a 
ISSN 1659-3316

Morales Harley Roberto

Estudios excelsos los de la gramática y literatura sánscritas, encerrados, hasta hace poco tiempo, en el impropio marco del doctorado de Letras, felizmente han hallado su adecuado asiento en la licenciatura de «Lenguas clásicas», cuyo nombre, ciertamente, no podría ostentar dentro de nuestra Facultad, si quedase reducida al cultivo de la filología occidental y se omitiere tan alta disciplina, como es la que abarca la lingüística indiana, origen venturoso del conocimiento científico de la gramática indoeuropea. (Daza, 1934, p. 7)

Desde el año académico 1935-1936 (García, 2008, pp. 23-34), la Facultad de Filosofía y Letras de la Universidad de Madrid ofrece, como parte de la licenciatura en Filología Clásica, el curso introductorio Lengua sánscrita y el curso monográfico Lengua y literatura sánscritas.

Actualmente, cinco universidades españolas ofrecen cursos de sánscrito. La Universidad Complutense de Madrid ofrece los citados cursos Antiguo Indio I, Antiguo Indio II y Literatura Clásica de la India, bajo la responsabilidad de la profesora Julia Mendoza Tuñón. La Universidad de Barcelona ${ }^{22}$ ofrece, a través de la Facultad de Filología, cursos de extensión de Lengua y Literatura Sánscritas en cuatro niveles y de Textos Sánscritos también en cuatro niveles, bajo la tutela de la profesora María Elena Sierra. La Universidad de Salamanca ofrece los citados cursos Lengua Sánscrita, Religiones y Filosofías de la India y Literatura India, gracias a la colaboración de los profesores Ana Agud Aparicio y Francisco Rubio Orecilla. La Universidad de Oviedo ofrece el citado curso Indio Antiguo, por parte del profesor Martín Sevilla Rodríguez. Y la Universidad de Murcia $^{23}$ ofrece, a través del Centro de Estudios del Próximo Oriente y la Antigüedad Tardía, cursos de Sánscrito en tres niveles y de Védico, a cargo del profesor Francisco Rubio Orecilla. Por último, vale la pena mencionar el reciente título propio de Especialista en Arte de India ${ }^{24}$, ofertado también por la Universidad Complutense de Madrid, en

\section{(c) (i)(2)}

La Revista Estudios es editada por la Universidad de Costa Rica y se distribuye bajo una Licencia Creative Commons Atribución-NoComercial-CompartirIgual 3.0 Costa Rica. Para más información envíe un mensaje a revistaestudios.eeg@ucr.ac.cr. 
el cual colaboran especialistas de varias universidades españolas para impartir cursos sobre arte, lengua, literatura, historia, filosofía, estética, religión, música, danza y hasta gastronomía de la India.

Para los estudios sobre la India en Latinoamérica, resulta de gran valor la lista, por país, que elaboran Martino y Ossa (2016, pp. 21-22). En primer término, cabe destacar, pese a que los estudios no son en lengua española, el caso de Brasil $^{25}$, especialmente en la Universidad de São Paulo; allí, los estudios de sánscrito han alcanzado, en opinión de De Mora (1983, p. 615), el mayor grado de desarrollo en la región, incluso con la creación de una carrera universitaria en Lengua y Literatura Sánscrita. A continuación, se brindan, por país y en orden cronológico según su fecha de inicio, los centros universitarios que brindan cursos propiamente de sánscrito.

En Perú, en 1958, comienzan, en la Universidad Nacional Mayor de San Marcos, los cursos (Rodríguez, 2016, p. 135) de sánscrito, pali, filosofía de la India, budismo e hinduismo, de la mano del profesor Fernando Tola Mendoza (1915-2017). Actualmente, en el Centro de Estudios Orientales de la Pontificia Universidad Católica del Perú, se ofrece el curso $^{26}$ Introducción a la lengua y a la cultura sánscrita, a cargo del profesor Pablo Carreño Cabrejos.

En México, en 1964, inician los estudios de sánscrito, con la fundación, en el Colegio de México, del Centro de Estudios de Asia y África. Allí, la profesora Hilda Chen-Apuy se gradúa, en 1965, como parte de la primera generación, de la maestría en Estudios Orientales (Picado, 2012, p. 5) y publica, en 1982, su traducción española de la Gramática elemental de la lengua sánscrita, del indólogo y sanscritista holandés Jan Gonda (1905-1991). Actualmente, en la maestría en Estudios de Asia y África de El Colegio de México, se ofrecen cursos $^{27}$ de Sánscrito en cuatro niveles, a cargo de los profesores Benjamín Preciado, Joshi Rasik Vihari, David Lorenzen, Adrián Muñoz y Sergio Rentería.

\section{(c) (i) (9) (2)}

La Revista Estudios es editada por la Universidad de Costa Rica y se distribuye bajo una Licencia Creative Commons Atribución-NoComercial-CompartirIgual 3.0 Costa Rica. Para más información envíe un mensaje a 
Además, en la Universidad Nacional Autónoma de México, desde 1973, por medio del Instituto de Investigaciones Filológicas, se llevan a cabo estudios indológicos (Phillips-Rodríguez, 2017, p. 15), gracias a los profesores Juan Miguel de Mora (1921-2017) y Ludwicka Jarocka; desde 2016, a través del Centro Regional de Investigaciones Multidisciplinarias, se desarrolla el proyecto Indología $\mathrm{UNAM}^{28}$, en el cual participan los profesores Óscar Figueroa, Elsa Cros, Benjamín Preciado, Wendy Phillips y Adrián Muñoz; y, desde 2017, adscrito a la Coordinación de Humanidades, existe el Programa Universitario de Estudios sobre Asia y África, el cual se remonta al Seminario Universitario de Estudios Asiáticos (2013). La Universidad Nacional Autónoma de México ofrece cursos como Literatura Sánscrita, Poesía mística en España y en la India, Cuentística hindú y su influencia en la literatura española medieval, El género picaresco en la literatura española y en la sánscrita, y Realismo mágico en la novela latinoamericana y a narrativa angloindia.

En Argentina, en 1970, se comienzan a impartir, en la Universidad de Buenos Aires, cursos (Rodríguez, 2016, p. 135) de Sánscrito y Filosofía de la India, de la mano del mencionado profesor Fernando Tola Mendoza, así como de la profesora Carmen Dragonetti. Actualmente, en la Universidad de Buenos Aires, las profesoras Rosalía Vofchuk, Gabriela Müller y Gabriel Martino son responsables del citado curso de Sánscrito; y, en la Universidad Nacional de La Plata $^{29}$, el profesor Emilio Federico Rollié, del Departamento de Letras de la Facultad de Humanidades y Ciencias de la Educación, dicta, desde el año 2003, un curso de Sánscrito, que el año 2012 toma la forma de Seminario de Introducción al Sánscrito y se ofrece como seminario de licenciatura para las carreras de Letras y Filosofía.

En Uruguay, para 1983 (De Mora, 1983, p. 615), la Facultad de Humanidades y Ciencias de la Universidad de la República ofrecía el curso de

\section{(C) $(00$}

La Revista Estudios es editada por la Universidad de Costa Rica y se distribuye bajo una Licencia Creative Commons Atribución-NoComercial-CompartirIgual 3.0 Costa Rica. Para más información envíe un mensaje a 
Sánscrito y cultura india, como materia troncal del bachillerato en Literatura con énfasis en Indología.

En Costa Rica, como se indicó, la fecha clave es 1968. La Universidad de Costa Rica es la primera en Centroamérica en incorporar estudios sobre culturas orientales, en general, y sobre la India y el sánscrito, en particular (Chen-Apuy, 1973, p. 90). A dos grandes maestras, pionera la una y continuadora la otra, se debe, en gran medida, este importante logro: respectivamente, Hilda Chen-Apuy Espinoza y Sol Argüello Scriba.

\section{Hilda Chen-Apuy Espinoza}

Hilda Chen-Apuy Espinoza (1923-2017 $7^{30}$ ) cursó estudios universitarios en Educación (Universidad de Costa Rica, 1941-1942); Historia del Arte, Filosofía del Arte y Literatura Norteamericana (Mount Holyoke, 1943-1944); Literatura Española (Universidad de lowa, 1944-1946); Arte y Cultura de la India (Universidad hindú de Benarés, 1956-1957); Estudios de Asia, con énfasis en historia cultural y en lengua sánscrita (El Colegio de México, 1964-1965); Estudios de India, China y lengua sánscrita (Universidad de Cambridge, 1966); y Estudios de India, el Sudeste Asiático y lengua sánscrita (Universidad de Ámsterdam, 1966-1968). Obtuvo una maestría en Artes por la Universidad de lowa (1946), una maestría en Estudios Orientales por El Colegio de México (1965) y un doctorado honoris causa en Letras Humanas por Mount Holoyoke College (2006).

Realizó estancias de investigación, muchas veces becada por la UNESCO, en India, Nepal y Ceilán (1956-1957); en India, Tailandia, Camboya y Japón (1968); por tercera ocasión en India (1975); en Japón (1977); en Taiwán (1978); nuevamente en Japón (1979); por cuarta ocasión en India (1982-1983); nuevamente en Taiwán (1984, 1986, 1988); por quinta ocasión en India (1989); y en Taiwán, Hong Kong y República Popular China (1993). Cabe destacar que el Gobierno de Japón la premió con la Orden del Tesoro Sagrado (1985). Además,

\section{(c) (1)(2)}

La Revista Estudios es editada por la Universidad de Costa Rica y se distribuye bajo una Licencia Creative Commons Atribución-NoComercial-CompartirIgual 3.0 Costa Rica. Para más información envíe un mensaje a 
ISSN 1659-3316 Junio 2019-Noviembre 2019

se desempeñó como docente en la Universidad de Costa Rica por casi cuatro décadas (1948-1984), en las Facultades de Educación (1948-1963), Ciencias y Letras (1958-1974), Letras (1968-1984), Ciencias Sociales (1977-1984) y Bellas Artes.

Entre sus publicaciones sobre la India, destacan La imagen de Buda en la India y en China (1963), El rostro velado de la India (1964), Rabindranath Tagore (1969), Los estudios orientales en la Universidad de Costa Rica (1973), Simbolismo y estética en el arte indio (1974), Evolución de la figura de Buda en la escultura de la India y China (1975), La integración del estudio de Asia y África en los programas de la Universidad de Costa Rica (1981), Gramática sánscrita (traducción de la obra de Gonda) (1982), El mensaje del Buddha y su expresión artística en India (1983) y Nacionalismo y arte en la India contemporánea (1983). Asimismo, fue miembro de la ALADAA (Asociación Latinoamericana de Estudios de Asia y África) desde su fundación (1976).

Por último, fue galardonada, entre otras condecoraciones, con el Premio Magón (2003) y el Premio Rodrigo Facio Brenes (2008), los reconocimientos más prestigiosos en el ámbito cultural que entregan, respectivamente, la República de Costa Rica y la Universidad de Costa Rica.

\section{Sol Argüello Scriba}

Sol Argüello Scriba (1953-), quien había sido asistente (1976-1982) de la profesora Hilda Chen-Apuy, se graduó como licenciada en Filología Clásica por la Universidad de Costa Rica (1984) y como máster en Literatura Clásica por esta misma institución (2014). Asumió, primero como profesora interina (1984) y después como docente en propiedad (1987), la Cátedra de Sánscrito y materias afines, en la Escuela de Filología, Lingüística y Literatura, donde ha impartido cursos de Sánscrito y Latín, ambos a nivel básico, intermedio y avanzado; así

\section{(C) $(0)$}

La Revista Estudios es editada por la Universidad de Costa Rica y se distribuye bajo una Licencia Creative Commons Atribución-NoComercial-CompartirIgual 3.0 Costa Rica. Para más información envíe un mensaje a 
ISSN 1659-3316

Junio 2019-Noviembre 2019

como de Literatura Sánscrita, Mitología de la India (curso que creó) y la obra de Rabindranath Tagore.

Ha sido profesora visitante en la Universidad de Extremadura $(2002,2004)$ y conferencista invitada en la Universidad de Sevilla $(2004,2007)$, en la Universidad de Salamanca (2011) y en la Universidad de Calcuta (2011). Asimismo, ha fungido como directora del Departamento de Filología Clásica de la Universidad de Costa Rica en dos ocasiones (2000-2004, 2012-2014).

Entre sus publicaciones sobre la India, destacan La lengua sánscrita, llegada y permanencia en Costa Rica (1989), Sāvitrī y la figura femenina en la literatura épica sánscrita (2000), Rabindranatnh Tagore at the University of Costa Rica (2002), La mujer-tradición en el cuento La pira fúnebre de Rabindranath Tagore (2002), Rabindranath Tagore y sus ideales sobre la educación (2004), Tagore, el poeta y el mundo (2007), Rabindranath Tagore en el Repertorio Americano (2011), La pertinencia de la enseñanza del sánscrito en el plan de estudios de Filología Clásica (2012), Del sánscrito al español. Préstamos remotos y adecuaciones (2012), Una comparación entre una fábula de Fedro y una fábula de Vișnuśarman (2012), Rabindranath Tagore y las Upanișads (2012), Tagore and Latin America: Some Considerations (2012), El cartero del rey o La libertad del ser humano (2012), La fábula de animales en las tradiciones literarias sánscrita, griega y latina (2013), Costa Rica (Chapter in Hundred Years of Tagore Reception: 1913-2013) (2013), Damayantī, de víctima a heroína o Una prueba de fidelidad (2015), El simbolismo de la serpiente en la fábula Las ranas que cabalgan la serpiente del Pañcatantra' (2017) y El pensamiento educativo de Rabindranath Tagore en dos grandes educadores costarricenses: Omar Dengo y Joaquín García Monge (2017). Igualmente, es miembro de la ALADAA (Asociación Latinoamericana de Estudios de Asia y África) desde 2008.

\section{(c) (i) (9) (2)}

La Revista Estudios es editada por la Universidad de Costa Rica y se distribuye bajo una Licencia Creative Commons Atribución-NoComercial-CompartirIgual 3.0 Costa Rica. Para más información envíe un mensaje a 


\section{El panorama actual}

En la Universidad de Costa Rica, a lo largo de estos 50 años de historia, los cursos Sánscrito Básico I y Sánscrito Básico II se han abierto a la población estudiantil de manera constante, durante el primer y el segundo ciclo lectivo respectivamente. Los grupos han variado en cantidad, desde uno solo hasta más de treinta alumnos. El curso Literatura Sánscrita ahora constituye una materia troncal del bachillerato en Filología Clásica. Los cursos Mitología de la India, Rabindranath Tagore y su obra se ofertan de manera constante y siempre se cuenta con estudiantes interesados. Los restantes niveles de Sánscrito (Intermedio I y II, Avanzado I y II) se ofrecen, ya sea como curso regular o bajo la modalidad de tutoría, a aquellos estudiantes que buscan continuar con esta especialización.

Junto a esta labor docente ${ }^{31}$, en la Escuela de Filología, Lingüística y Literatura se han inscrito varios proyectos de investigación ${ }^{32}$ cuya temática gira en torno a la India antigua y se han desarrollado varias actividades de acción social ${ }^{33}$ para divulgar esta cultura milenaria. Además, en el marco de los Coloquios de Filología y Literatura Clásicas que, de forma bienal, organiza el Departamento de Filología Clásica, se han presentado varias ponencias ${ }^{34}$ de temas afines a la India. Finalmente, hay algunos trabajos finales de graduación ${ }^{35}$, tanto de la licenciatura en Filología Clásica como de la maestría en Literatura Clásica ${ }^{36}$, que abordan lo indio antiguo como clásico.

\section{Conclusiones}

El profesor emérito y humanista costarricense Manuel Antonio Quirós Rodríguez (1937-2014) decía, en el curso de Introducción a la Filología, lo siguiente $^{37}$ : "Académicamente, no hay que ser egoísta, porque todo lo que uno sabe lo aprendió de alguien más". Si hoy se cumplen 50 años de enseñanza del

\section{(C) $(\Theta \odot$}

La Revista Estudios es editada por la Universidad de Costa Rica y se distribuye bajo una Licencia Creative Commons Atribución-NoComercial-CompartirIgual 3.0 Costa Rica. Para más información envíe un mensaje a revistaestudios.eeg@ucr.ac.cr. 
ISSN 1659-3316

Junio 2019-Noviembre 2019

Morales Harley Roberto

sánscrito en la Universidad de Costa Rica es porque alguien tuvo la iniciativa, pero también porque alguien más la mantuvo.

El sánscrito se ha de mantener, en la Universidad de Costa Rica y en el Departamento de Filología Clásica, por las siguientes razones:

a) En virtud de su ubicación en la familia lingüística indoeuropea, el sánscrito facilita el aprendizaje de una gran cantidad de lenguas del mundo.

b) A causa de los sanscritismos que se han incorporado al español, el sánscrito permite ampliar las posibilidades de abordaje etimológico de esta lengua en particular.

c) En tanto variedad lingüística del indoario antiguo, el sánscrito abre las puertas a la literatura, la mitología, la religión, la filosofía, la historia y la ciencia de una civilización milenaria.

d) Gracias a la existencia de hablantes nativos y de todo movimiento de revitalización, el sánscrito ofrece una vía de acceso a la cotidianeidad de una buena parte del pueblo indio.

e) Debido a que cuenta con una magna producción literaria, cuantitativa y cualitativamente, el sánscrito se presenta como lengua de cultura.

f) En la medida en que se entienda como una lengua clásica, el sánscrito forma parte integral del patrimonio humano y, como tal, somos afortunados de haberlo heredado y estamos en la obligación de preservarlo.

g) Así como el mundo grecolatino sirve de puente temporal entre el pasado y el presente, de manera análoga, la India antigua funciona, por medio del sánscrito, como punto de encuentro entre Oriente y Occidente.

h) Si los clásicos grecolatinos pasan, actualmente, por un periodo crítico, en la medida en que varios países del mundo se cuestionan acerca de su utilidad, el

La Revista Estudios es editada por la Universidad de Costa Rica y se distribuye bajo una Licencia Creative Commons Atribución-NoComercial-CompartirIgual 3.0 Costa Rica. Para más información envíe un mensaje a revistaestudios.eeg@ucr.ac.cr. 
complemento que a ellos ofrecen los estudios sánscritos, como parte de la tradición y, en consecuencia, como vía para la comprensión de la cultura de India -una nación cuyo incremento demográfico y cuyo crecimiento económico la perfilan como una de las grandes potencias mundiales-, representan un sólido asidero.

i) Si los últimos años han sido testigos del fortalecimiento de las relaciones culturales entre India y Latinoamérica, en general, y entre India y Costa Rica, en particular, ¿por qué el alza en el número de academias de yoga, estéticas, tiendas de ropa y restaurantes de comida india no habría de aparejarse con un fuerte impulso a los estudios de sánscrito?

\section{Notas}

${ }^{1}$ Plan de estudios de la carrera de bachillerato y licenciatura en Filología Clásica. http://www.cea.ucr.ac.cr/index.php/component/jdownloads/send/70-filologia/246bachillerato-y-licenciatura-en-filologia-espanola-plan-1

${ }^{2}$ En la Universidad Nacional Autónoma de México, desde el año 2009, el sánscrito es incluido, como lengua clásica indoeuropea (Phillips-Rodríguez, 2017, pp. 1617), en los estudios del Centro de Estudios Clásicos del Instituto de Investigaciones Filológicas, así como en las publicaciones de la revista Nova Tellus.

${ }^{3}$ En la Universidad de Buenos Aires, el curso Sánscrito es ofrecido, como materia electiva de grado, por el Departamento de Lenguas y Literaturas Clásicas de la Facultad de Filosofía y Letras. http://letrasclasicas.filo.uba.ar/content/plan-deestudios.

\section{(C) $(00$}

La Revista Estudios es editada por la Universidad de Costa Rica y se distribuye bajo una Licencia Creative Commons Atribución-NoComercial-CompartirIgual 3.0 Costa Rica. Para más información envíe un mensaje a 
ISSN 1659-3316

Junio 2019-Noviembre 2019

Morales Harley Roberto

4 En la Universidade de São Paulo, los cursos Introdução ao Sânscrito I, Introdução ao Sânscrito II, Introdução ao Sânscrito III, Introdução ao Sânscrito IV, Sânscrito V: Tradução Literária y Sânscrito VI: Tradução Literária son ofrecidos, como materias electivas de grado, por el Departamento de Letras Clássicas e Vernáculas de la Facultade de Filosofia, Letras e Ciências Humanas. https://uspdigital.usp.br/jupiterweb/obterDisciplina?sgldis=\&nomdis=sanscrito.

${ }^{5}$ En la Brown University, específicamente en el Department of Classics de la Faculty of Humanities, a nivel de grado, la carrera de Classics tiene los énfasis de Classics, Greek, Latin, Greek and Latin, South Asian Classics, Sanskrit, Greek and $\begin{array}{lllll}\text { Sanskrit } & \mathrm{y} & \text { Latin }\end{array}$ https://www.brown.edu/academics/classics/academics/undergraduate-program. Asimismo, a nivel de posgrado, los cursos Sanskrit 1020 (Religious Literature), Sanskrit 1080 (Mahābhārata), Sanskrit 1100 (Vedic Sanskrit), Sanskrit 1400 (Pāṇini), Sanskrit 1600 (belles lettres, kāvya) y Sanskrit 1800 (Classical Philosophy, darśanas) son ofrecidos, como materias troncales de los énfasis en Sanskrit Language and Literature y en Classics and Sanskrit. https://www.brown.edu/academics/classics/academics/graduate-program/phdprograms/sanskrit.

${ }^{6}$ En la Cornell University, los cursos Elementary Sanskrit I, Elementary Sanskrit II, Intermediate Sanskrit I, Intermediate Sanskrit II, Advanced Sanskrit I y Advanced Sanskrit II son ofrecidos, como materias electivas de grado, por el Department of Classics del College of Arts and Sciences. https://classics.cornell.edu/courses

${ }^{7}$ En el Lebanon Valley College, los cursos Elementary Sanskrit I y Elementary Sanskrit II son ofrecidos, junto a los niveles básicos de latín y griego, en el World Classics Minor. https://www.lvc.edu/academics/programs-of-study/religion/worldclassics-minor/

\footnotetext{
(c) (1)(2)

La Revista Estudios es editada por la Universidad de Costa Rica y se distribuye bajo una Licencia Creative Commons Atribución-NoComercial-CompartirIgual 3.0 Costa Rica. Para más información envíe un mensaje a revistaestudios.eeg@ucr.ac.cr.
} 
Revista Estudios, (38), 2019.

Junio 2019-Noviembre 2019

ISSN 1659-3316

Morales Harley Roberto

${ }^{8}$ En la State University of New York at Buffalo, los cursos Sanskrit 1 y Sanskrit 2 son ofrecidos, como materias electivas de grado, por el Department of Classics del College of Arts and Sciences. https://catalog.buffalo.edu/courses/classics.html.

${ }^{9}$ En la University of Florida, el curso Beginning Sanskrit es ofrecido, como materia electiva de grado y de posgrado, por el Department of Classics del College of Liberal Arts and Sciences. https://classics.ufl.edu/2017/07/23/beginning-sanskritfor-cs-majors-and-graduate-students/.

${ }^{10}$ En la University of Georgia, los cursos Sanskrit I y Sanskrit II son ofrecidos, como materias electivas de grado, por el Department of Classics del College of Arts and Sciences. https://www.classics.uga.edu/courses/undergraduate.

${ }^{11}$ En la University of Vermont, los cursos Introductory Sanskrit I e Introductory Sanskrit II son ofrecidos, como materias electivas de grado, por el Department of Classics del College of Arts and Sciences. http://www.uvm.edu/academics/courses/?subject $=C L A S \&$ number $=196 \&$ term $=\& s e c$ tion\&action=Search.

${ }^{12}$ En la University of Rochester, el curso Sanskrit es ofrecido, como materia electiva de grado, por el Department of Religion and Classics de la School of Arts and Sciences. https://www.sas.rochester.edu/rel/courses/index.html.

${ }^{13}$ En la Concordia University, el curso Sanskrit es ofrecido, como materia electiva de grado, por el Department of Classics, Modern Languages and Linguistics de la Faculty of Arts and Science. http://www.concordia.ca/academics/undergraduate/calendar/current/sec31/31060.html\#a31.060.1.

${ }^{14}$ En la Universidad Complutense de Madrid, los cursos Antiguo indio I, Antiguo indio II y Literatura clásica de la India son ofrecidos, como materias electivas de

\section{(C) $(00$}

La Revista Estudios es editada por la Universidad de Costa Rica y se distribuye bajo una Licencia Creative Commons Atribución-NoComercial-CompartirIgual 3.0 Costa Rica. Para más información envíe un mensaje a revistaestudios.eeg@ucr.ac.cr. 
grado, por el Departamento de Filología Clásica de la Facultad de Filología. https://www.ucm.es/estudios/grado-filologiaclasica-acceso-informacion.

${ }^{15}$ En la Universidad de Salamanca, los cursos Lengua Sánscrita, Religiones y Filosofías de India y Literatura India son ofrecidos, como materias de extensión en el diploma de extensión universitaria en lenguas y culturas de India e Irán, por el Departamento de Filología Clásica e Indoeuropeo de la Facultad de Filología. http://www.usal.es/diploma-de-extension-universitaria-en-lenguas-y-culturas-deindia-e-iran-online/asignaturas.

${ }^{16}$ En la Universidad de Oviedo, el curso Indio Antiguo es ofrecido, como materia electiva de grado, por el Departamento de Filología Clásica y Románica de la Facultad de Filosofía y https://directo.uniovi.es/catalogo/Tipo Asignaturas.asp?plan=LFILOCLA.

${ }^{17}$ En la Oxford University, específicamente en la Faculty of Classics, la carrera de Classics ofrece los siguientes énfasis: Classics, Classical Archaeology and Ancient History, Ancient and Modern History, Classics and English, Classics and Modern Languages y Classics and Oriental Studies. https://www.classics.ox.ac.uk/courses.

18 Agradezco enormemente la colaboración de la M.L. Sol Argüello Scriba, profesora jubilada de sánscrito de la Universidad de Costa Rica, para la sección de Costa Rica; de la Dra. Wendy Phillips-Rodríguez, de la Universidad Nacional Autónoma de México, para la sección de México; del Lic. Emilio Federico Rollié, de la Universidad Nacional de La Plata, para la sección de Argentina; y del Dr. Francisco Rubio Orecilla, de la Universidad de Salamanca, para la sección de España.

19

Oxford

University

https://www.ox.ac.uk/admissions/undergraduate/courses/oriental-

studies/sanskrit?wssl=1, Cambridge University https://www.ames.cam.ac.uk/research/research-language/sanskrit-studies,

La Revista Estudios es editada por la Universidad de Costa Rica y se distribuye bajo una Licencia Creative Commons Atribución-NoComercial-Compartirlgual 3.0 Costa Rica. Para más información envíe un mensaje a revistaestudios.eeg@ucr.ac.cr. 
Revista Estudios, (38), 2019.

Junio 2019-Noviembre 2019

ISSN 1659-3316

Morales Harley Roberto

University of London https://www.soas.ac.uk/southasia/languages/sanskrit/, University of Edinburgh https://www.ed.ac.uk/literatures-languages-cultures/asianstudies/sanskrit.

20 Deutsche Welle http://m.dw.com/en/the-west-has-a-lot-to-learn-from-ancientindia-indology-in-germany/a-6635426.

21

Columbia

University.

http://www.columbia.edu/cu/mesaas/languages/sanskrit/centers.html.

22

Universitat

de

Barcelona.

https://www.ub.edu/dyn/cms/continguts es/estudis/oferta formativa/extensions/ind ex.html.

${ }^{23}$ Universidad de Murcia. https://www.um.es/cepoat/?page id=1091.

24

Universidad

Complutense

de

Madrid.

https://www.ucm.es/titulospropios/arteindia/profesorado.

${ }^{25}$ La enseñanza ha sido sostenida por la labor de los profesores Izidoro Blikstein, Carlos Alberto da Fonseca, Mário Ferrerira, Maria Valíria, Aderson de Melo Vargas, Lilian Proença de Menezes Montenegro y Elisa Fumiko Kikuchi Tamajusuku.

26

Pontificia Universidad

Católica

del

Perú.

http://ceo.pucp.edu.pe/seminarios/seminarios-2018-2/.

27 El Colegio de México. https://ceaa.colmex.mx/plan-de-estudios-cursos-ybibliografia-relevante.

28

Universidad

Nacional

Autónoma

de

México.

http://indologia.crim.unam.mx/indo/?q=node/1.

\section{(c) (i) (2) (2)}

La Revista Estudios es editada por la Universidad de Costa Rica y se distribuye bajo una Licencia Creative Commons Atribución-NoComercial-CompartirIgual 3.0 Costa Rica. Para más información envíe un mensaje a revistaestudios.eeg@ucr.ac.cr. 


\section{http://www.fahce.unlp.edu.ar/academica/areas/letras/descargables/sanscrito-}

\section{8/view.}

${ }^{30}$ El año 2017, con el fallecimiento de los profesores Hilda Chen-Apuy Espinoza, Juan Miguel de Mora y Fernando Tola Mendoza, marca el final de una época en los estudios indológicos latinoamericanos.

${ }^{31}$ En otras unidades académicas de la Universidad de Costa Rica también se imparten cursos sobre la India. Por ejemplo, en la Escuela de Filosofía, la profesora Katherine Masís Iverson imparte el curso F-6052 y RP-1229 Introducción a la mística hindú y budista; y, en la Escuela de Artes Plásticas, los profesores Mercedes González Kreysa y Carlos Calderón Herrera imparten los cursos AP1030 Arte de la India, AP2023 Arte budista de Asia, AP2028 Arte oriental y AP6075 El origen de la imagen antes de la era del arte.

${ }^{32}$ De Sol Argüello Scriba, Traducción al español de fábulas en sánscrito de la India: Libro I del Pañcatantra (2011-2014). De Roberto Morales Harley, Argumentación en la literatura griega y sánscrita (2015-2017) y El héroe épico: Aquiles y Héctor en la llíada, Arjuna y Karṇa en el Mahābhārata (Vigente).

${ }^{33}$ Seminario "Rabindranath Tagore, un puente entre dos mundos: India y Costa Rica" (2011), a cargo de los profesores visitantes Shyama Prasad Ganguly e Indranil Chakravarty de la Jawaharlal Nehru University; conversatorio "La actualidad y riqueza del Mahābhārata" (2017), con los profesores Sol Argüello Scriba y Roberto Morales Harley, en el marco de la celebración de los 120 años del Teatro Nacional de Costa Rica; y un nuevo seminario "Rabindranath Tagore" (2018), gracias a los profesores visitantes Dibyajyoti Mukhopadhyay, Subrata Guha, Shatabdi Ghosh, Saptami Ghosh, Sugata Guha y Debleena Bandyopadhyay.

\section{(C) $(00$}

La Revista Estudios es editada por la Universidad de Costa Rica y se distribuye bajo una Licencia Creative Commons Atribución-NoComercial-CompartirIgual 3.0 Costa Rica. Para más información envíe un mensaje a 
${ }^{34}$ En el I Coloquio, Káñina XXXVI (1), de Sol Argüello Scriba, La pertinencia de la enseñanza del sánscrito en el plan de estudios de Filología Clásica. En el II Coloquio, Káñina XXXIX (3), de Sol Argüello Scriba, La permanencia de las imágenes femeninas de los textos épicos en la India; de Annette Calvo Shadid y Zaida Rojas Cabezas, Los términos sánscritos del yoga: Una travesía milenaria. En el III Coloquio, Káñina XLI (3), de Sol Argüello Scriba, El simbolismo de la serpiente en la fábula Las ranas que cabalgan la serpiente del Pañcatantra; de Roberto Morales Harley, El mito en los discursos del Mahābhārata; de Annette Calvo Shadid, Sobre la vitalidad de las 'lenguas muertas' y su enseñanza en la Universidad de Costa Rica. Y, en el IV Coloquio (En prensa), de Roberto Morales Harley, Ambā: la venganza femenina en el Mahābhārata. https://revistas.ucr.ac.cr/index.php/kanina/issue/archive.

${ }^{35}$ De Sol Argüello Scriba, la tesis de grado Del Pañcatantra: El brahmán que hizo castillos en el aire. Traducción y estudio (1984) y la tesis de posgrado De la fábula india hasta la fábula de la Edad Media a través de la tradición griega y latina (2014); de Roberto Morales Harley, la tesis de grado Sāvitrī y Orfeo: traducción y análisis comparativo de los discursos en el contexto del encuentro con los dioses de la muerte (2011) y la tesis de posgrado Los discursos de embajada ante Duryodhana (Mahābhārata V) y Aquiles (Ilíada IX): formas de argumentación en el contexto guerrero épico (2015).

${ }^{36}$ En esta maestría, además, se han impartido dos cursos de posgrado sobre la India: SP-7792 La fábula: teoría y tradición en la India y Occidente (2015), por parte de la profesora Sol Argüello Scriba, y SP- Diosas y dioses de la India: Un recorrido por la iconografía del hinduismo (2015), a cargo de la profesora visitante Wendy Phillips-Rodríguez de la Universidad Nacional Autónoma de México.

${ }^{37}$ La cita procede de los apuntes de clase del autor de este trabajo.

\section{(c) (i)(2)}

La Revista Estudios es editada por la Universidad de Costa Rica y se distribuye bajo una Licencia Creative Commons Atribución-NoComercial-Compartirlgual 3.0 Costa Rica. Para más información envíe un mensaje a 


\section{Bibliografía}

Álvarez-Pedrosa, J. (1994). La lingüística indoeuropea en España hasta 1930. Revista Española de Lingüística, 24(1), 49-67.

Argüello, S. (1989). La lengua sánscrita, llegada y permanencia en Costa Rica. Káñina, 13(1-2), 61-63.

Argüello, S. (2008). Acta de la Comisión Dictaminadora Premio Rodrigo Facio Brenes 2008. San José: Universidad de Costa Rica.

Argüello, S. (2012). La pertinencia de la enseñanza del sánscrito en el plan de estudios de Filología Clásica. Káñina, 36(1), 73-82.

Burrow, T. 1965. The Sanskrit Language. London: Faber and Faber.

Chen-Apuy, H. 1973. Los estudios orientales en la Universidad de Costa Rica. Estudios Orientales, 8(1), 88-90.

Daza, M. (1934). Proemio. En González, P. (traductor). Ratnāvalī o El collar de perlas de ÇriHarșa (pp. 7-124). Madrid: Victoriano Suárez.

De Mora, J. 1983. Sanskrit Studies in Latin America. Journal of the American Oriental Society, 103(3), 615-616.

Departamento de Investigación y Bibliografía de la Biblioteca Nacional Miguel Obregón Lizano. (2002). Roberto Brenes Mesén, 1874-1947: bibliografía. San José: Ministerio de Cultura, Juventud y Deportes.

García, F. (2008). El nacimiento de la Filología Clásica en España. La Facultad de Filosofía y Letras de Madrid. Estudios Clásicos, 134, 1-28.

Gonda, J. (1982). Gramática sánscrita. Traducción de Hilda Chen-Apuy Espinoza. México, D.F.: El Colegio de México.

\section{(c) (i) (2) (2)}

La Revista Estudios es editada por la Universidad de Costa Rica y se distribuye bajo una Licencia Creative Commons Atribución-NoComercial-CompartirIgual 3.0 Costa Rica. Para más información envíe un mensaje a revistaestudios.eeg@ucr.ac.cr. 
Martino, G. y Ossa, J. (2016). Los estudios de la India en Latinoamérica. Desarrollo, integración y perspectivas futuras. Revista Guillermo de Ockham, 14(1), 17-23.

Matarrita, E. (1989). Lo clásico: Una interpretación y una reflexión. Káñina, 13(12), 55-59.

Müller, G. y Orqueda, V. (2016). Algunos problemas en torno a la noción de sánscrito clásico. Revista Guillermo de Ockham, 14(1), 135-139.

Mylius, K. (2015). Historia de la literatura india antigua. Madrid: Trotta.

Perry, E. (1936). A Sanskrit Primer. New York: Columbia University Press.

Phillips-Rodríguez, W. (2017). Los estudios indológicos en el IIFL: crónica de un nacimiento anunciado. En Figueroa, Ó. La mirada anterior. Poder visionario e imaginación en India antigua (pp. 15-19). México: UNAM.

Picado, A. (2012). Semblanza en el día internacional de la mujer: 8 de marzo. Hilda Chen Apuy Espinoza. Conexiones, 4(1), 4-7.

Real Academia Española. (2014). Diccionario de la lengua española. En http://www.rae.es/

Rodríguez, L. (2016). De buddhas y bodhisattvas: Homenaje a Fernando Tola Mendoza. Revista Guillermo de Ockham, 14(1), 107-114.

\section{(c) (i) (2)}

La Revista Estudios es editada por la Universidad de Costa Rica y se distribuye bajo una Licencia Creative Commons Atribución-NoComercial-Compartirlgual 3.0 Costa Rica. Para más información envíe un mensaje a 